\title{
Editorial
}

\section{SUICIDE AND SCHIZOPHRENIA}

\author{
Ahmad $\mathrm{M}^{1}$, Ali $\mathrm{M}^{2}$
}

The word suicide has been derived from Latin word -suicidium (sui caedere), means "to kill oneself". It is the 10th leading cause of death worldwide involving death of $8,00,000$ people each year ${ }^{1}$. Rates are three to four times higher in men than in women $^{2,3}$. There are an estimated 10 to 20 million non-fatal attempted suicides every year ${ }^{4}$.

Mental disorders are often present at the time of suicide with estimates ranging from $27 \%$ to $90 \%$. Patients, who have been admitted to a psychiatric unit, have a lifetime risk of completed suicide (8.6\%). Half of all people who die by suicide have major depressive disorder; like-schizophrenia, personality disorders ,bipolar disorder, posttraumatic stress disorder, eating disorders etc ${ }^{6-9}$. Approximately $20 \%$ of suicides have had a previous attempt and of that $1 \%$ complete suicide within a year and more than $5 \%$ commit suicide after 10 years. Presence of self-injurious behaviour is related to increase suicide risk. Individuals who are at risk for suicide are more likely to make an attempt, when they have command auditory hallucinations ${ }^{10}$.

There is no known underlying pathophysiology for either suicide or depression. It is however believed to result from interplay of behavioural, socio-environmental and psychiatric factors. Low levels of brain-derived neurotrophic factor (BDNF) is directly associated with suicide ${ }^{11}$ and indirectly associated through its role in major depression, post-traumatic stress disorder, schizophrenia and obsessive-compulsive disorder ${ }^{12}$.

Biological contributors to suicidal behaviour in schizophrenia have been examined via family history, monoamine metabolites in cerebrospinal fluid (CSF), candidate gene allele variants. Family history was found to be associated with suicidal behaviour across diagnostic groups ${ }^{13}$. Serotonin and norepinephrine have been the primary neurotransmitters investigated in suicidal behaviour.
CSF metabolites like homovanillic acid and 3-methoxy-4-hydroxy-phenylglycol have not differentiated suicidal and nonsuicidal individuals with schizophrenia ${ }^{14-17}$, but CSF 5-hydroxyindole acetic acid (5-HIAA) has been found to relate to suicide intention and lethality in patients with schizophrenia who attempt suicide ${ }^{18-20}$.

Forensic Pathologists performed Post-mortem studies have found reduced levels of brain derived neurotrophic factors (BDNF) in the hippocampus and prefrontal cortex, in those with psychiatric conditions $^{21}$. Serotonin, a brain neurotransmitter, is believed to be low in those who commit suicide. This is partly based on evidence of increased levels of 5-HT2A receptors found after death ${ }^{22}$. Epigenetics, the study of changes in genetic expression in response to environmental factors is also believed to play a role in determining suicide risk ${ }^{23}$. Treatment with medication and cognitive-behavioral therapy (CBT) reduces suicidal behavior ${ }^{24}$. Some investigators suggest that treatment with new generation antipsychotics, clozapine and olanzapine have been found to reduce suicidal behavior in those with schizophrenia ${ }^{25}$.

"Psychosocial factors related to attempted suicide in schizophrenic patients" by Islam MM et al in this issue of JAFMC is a time worthy work. We believe that this publication will enrich our knowledge and encourage others to perform more studies in future on this subject, based on our countries perspective and considering more variables of data like sociodemographic: gender, ethnicity, religion, civil status, children, employment, social class; family history: psychiatric disorder, depression, alcohol misuse, suicide; personal history: childhood broken home/parental loss, education, IQ, living circumstances, recent loss and life events; clinical history: positive symptoms of schizophrenia, delusions, hallucinations (command), paranoia, suspiciousness, negative symptoms of schizophrenia,

1. Lt Col Mushtaq Ahmad, MBBS, DFM, MCPS, FRSPH, Associate Professor \& Head of the Department of Forensic Medicine \& Toxicology, AFMC, Dhaka Cantonment; 2. Brig Gen Mohammad Ali, MBBS, DPH, M.Phil (PSM), Professor \& Head of the Department of Community Medicine, AFMC, Dhaka Cantonment. 
flat affect, social withdrawal, agitation/motor restlessness, worthlessness/low self-esteem, hopelessness, sleep disturbance, insight, fear of mental disintegration, medication, adherence to treatment, compulsory admission, attempted suicide, suicide threats or ideation, depression (past and recent), alcohol misuse / dependence, drug misuse / dependence, substance misuse/dependence (drugs and/or alcohol), violence, impulsivity, hostility, suspiciousness, anxiety, social relationships and physical illness etc.

\section{References}

1. Hawton K, van Heeringen K. "Suicide". Lancet April 2009; 373 (9672): 1372-81.

2. Värnik, P "Suicide in the world.". International journal of environmental research and public health 2012 Mar; 9 (3): $760-71$.

3. Meier, Marshall B. Clinard, Robert F. Sociology of deviant behavior 2008 (14th ed.). Belmont, CA: Wadsworth Cengage Learning. p.169.

4. Bertolote JM, Fleischmann A. "Suicide and psychiatric diagnosis: a worldwide perspective". World Psychiatry 2002;1 (3): 181-5.

5. Chehil, Stan Kutcher, Sonia Suicide Risk Management A Manual for Health Professionals. 2012 (2nd ed. ed.). Chicester: John Wiley \& Sons. pp.30-33.

6. Bertolote, JM; Fleischmann, A; De Leo, D; Wasserman, D. "Psychiatric diagnoses and suicide: revisiting the evidence.". Crisis 2004; 25 (4): 147-55.

7. Kapur S. Schizophrenia. Lancet. 2009; 374(9690):635-45.

8. Tintinalli, Judith E.. Emergency Medicine: A Comprehensive Study Guide (Emergency Medicine (Tintinalli)). 2010 New York: McGraw-Hill Companies. pp. 1940-1946.

9. Whitlock J, Knox KL. "The relationship between self-injurious behavior and suicide in a young adult population". Arch Pediatr Adolesc Med 2007;161 (7): 634-40.

10. Harkavy-Friedman JM, Kimhy D, Nelson EA, et al. Suicide attempts in schizophrenia: the role of command auditory hallucinations for suicide. J Clin Psychiatry. 2003; 64:871-874.

11. Pjevac, M; Pregelj, P. "Neurobiology of suicidal behaviour.". Psychiatria Danubina. 2012; 24 Suppl 3: S336-41.
12. Sher, L. "The role of brain-derived neurotrophic factor in the pathophysiology of adolescent suicidal behavior.". International journal of adolescent medicine and health 2011; 23 (3): 181-5.

13. Tremeau F, Staner L, Duval F, et al. Suicide attempts and family history of suicide in three psychiatric populations. Suicide Life Threat Behav. 2005;35:702-713.

14. Ninan PT, van Kammen DP, Scheinin M, et al. CSF 5-hydroxyindoleacetic acid levels in suicidal schizophrenic patients. Am J Psychiatry. 1984;141:566-569.

15. Roy A, Ninan P, Mazonson A, et al. CSF monoamine metabolites in chronic schizophrenic patients who attempt suicide. Psychol Med. 1985;15:335-340.

16. Cooper SJ, Kelly CB, King DJ. 5-Hydroxyindoleacetic acid in cerebrospinal fluid and prediction of suicidal behaviour in schizophrenia. Lancet. 1992;340:940-941.

17. Lemus CZ, Lieberman JA, Johns CA, et al. CSF 5-hydroxyindoleacetic acid levels and suicide attempts in schizophrenia. Biol Psychiatry. 1990;27:926-929.

18. Harkavy-Friedman JM, Haas GL, Nelson E, et al. CSF metabolites and clinical features of schizophrenia: relationship to suicidal behavior. Paper presented at: American College of Neuropsychopharmacology; December 14, 1998; Las Croabas, Puerto Rico.

19. De Luca V, Tharmalingam S, Muller DJ, et al. Gene-gene interaction between MAOA and COMT in suicidal behavior: analysis in schizophrenia. Brain Res. 2006; 1097:26-30.

20. Li D, Duan Y, He L. Association study of serotonin 2A receptor (5-HT2A) gene with schizophrenia and suicidal behavior using systematic meta-analysis. Biochem Biophys Res Commun. 2006;340:1006-1015.

21. Sher, L. "Brain-derived neurotrophic factor and suicidal behavior.". QJM : monthly journal of the Association of Physicians 2011;104 (5): 455-8.

22. Dwivedi, Yogesh. The neurobiological basis of suicide. 2012;Boca Raton, FL: Taylor \& Francis/CRC Press. p.166.

23. Autry, AE; Monteggia, LM . "Epigenetics in suicide and depression.". Biological Psychiatry 2009;66 (9): 812-3.

24. Tiihonen J, Walhbeck K, Lonnqvist J, et al. Effectiveness of antipsychotic treatments in a nationwide cohort of patients in community care after first hospitalisation due to schizophrenia and schizoaffective disorder: observational follow-up study. BMJ. 2006;333:224

25. Leucht S, Heres S. Epidemiology, clinical consequences, and psychosocial treatment of nonadherence in schizophrenia. J Clin Psychiatry. 2006;67:3-8. 